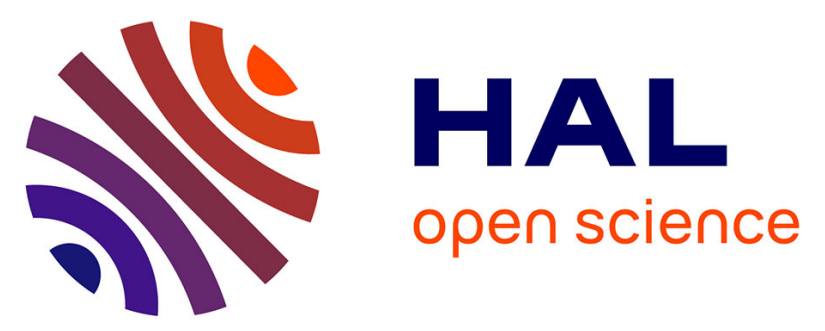

\title{
The anti-nuclease humoral immune response of broiler chickens exposed to Staphylococcus aureus, infectious bursal disease virus and chicken anaemia virus in an experimental model for bacterial chondronecrosis and osteomyelitis.
}

John David Rodgers, John Mccullagh, Perpetua Mcnamee, Joan A Smyth, Hywel Ball

\section{- To cite this version:}

John David Rodgers, John Mccullagh, Perpetua Mcnamee, Joan A Smyth, Hywel Ball. The antinuclease humoral immune response of broiler chickens exposed to Staphylococcus aureus, infectious bursal disease virus and chicken anaemia virus in an experimental model for bacterial chondronecrosis and osteomyelitis.. Avian Pathology, 2006, 35 (04), pp.302-308. 10.1080/03079450600821174 . hal00540054

\author{
HAL Id: hal-00540054 \\ https://hal.science/hal-00540054
}

Submitted on 26 Nov 2010

HAL is a multi-disciplinary open access archive for the deposit and dissemination of scientific research documents, whether they are published or not. The documents may come from teaching and research institutions in France or abroad, or from public or private research centers.
L'archive ouverte pluridisciplinaire HAL, est destinée au dépôt et à la diffusion de documents scientifiques de niveau recherche, publiés ou non, émanant des établissements d'enseignement et de recherche français ou étrangers, des laboratoires publics ou privés. 


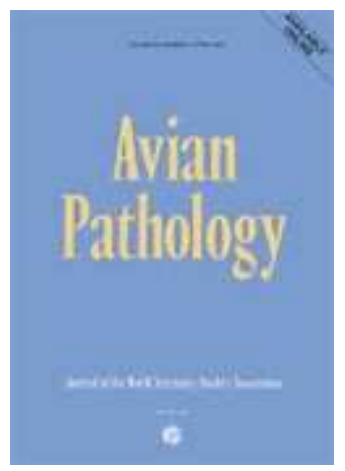

The anti-nuclease humoral immune response of broiler chickens exposed to Staphylococcus aureus, infectious bursal disease virus and chicken anaemia virus in an experimental model for bacterial chondronecrosis and osteomyelitis.

\begin{tabular}{|r|l|}
\hline Journal: & Avian Pathology \\
\hline Manuscript ID: & CAVP-2006-0024.R1 \\
\hline Manuscript Type: & Original Research Paper \\
\hline Date Submitted by the & O6-Apr-2006 \\
\hline Complete List of Authors: & $\begin{array}{l}\text { RODGERS, JOHN; The Queen's University of Belfast, Veterinary } \\
\text { Science } \\
\text { McCullagh, John; The Queen's University of Belfast, Veterinary } \\
\text { Science } \\
\text { McNamee, Perpetua; Department of Agriculture for Northern } \\
\text { Ireland, Veterinary Science } \\
\text { Smyth, Joan; University of Connecticut, Pathobiology \& Veterinary } \\
\text { Science } \\
\text { Ball, Hywel; Department of Agriculture for Northern Ireland, } \\
\text { Veterinary Science }\end{array}$ \\
\hline \hline Keywords: & $\begin{array}{l}\text { CHICKEN, STAPHYLOCOCCUS AUREUS, INFECTIOUS BURSAL } \\
\text { DISEASE VIRUS, CHICKEN ANEMIA VIRUS }\end{array}$ \\
\hline \hline
\end{tabular}

\section{SCHOLARONE Manuscripts}


Cavp-2006-0024

The anti-nuclease humoral immune response of broiler chickens exposed to Staphylococcus aureus, infectious bursal disease virus and chicken anaemia virus in an experimental model for bacterial chondronecrosis and osteomyelitis

John D. Rodgers ${ }^{1 *}$, John J. McCullagh ${ }^{1}$, Perpetua T. McNamee ${ }^{2}$, Joan A. Smyth ${ }^{3}$ and Hywel J. Ball ${ }^{3}$.

1. Department of Veterinary Science, The Queen's University of Belfast, Stormont, Belfast, BT4 3SD, Northern Ireland. 2. Veterinary Sciences Division, Department of Agriculture and Rural Development for Northern Ireland, 43 Beltany Road, Omagh, BT78 5NF, Northern Ireland. 3. Veterinary Sciences Division, Department of Agriculture and Rural Development for Northern Ireland, Stormont, Belfast, BT4 3SD, Northern Ireland.

Short Title: Anti-nuclease humoral immune response

*Corresponding author.

Mailing Address: Department of Veterinary Science, The Queen's University of Belfast, Stoney Road, Stormont, Belfast, BT4 3SD, Northern Ireland.

Phone +4402890 525740. Fax +4402890525745.

E-mail j.rodgers@qub.ac.uk

Received 16 February 2006

Cavp-2006-0024 
The anti-nuclease humoral immune response of broiler chickens exposed to Staphylococcus aureus, infectious bursal disease virus and chicken anaemia virus in an experimental model for bacterial chondronecrosis and osteomyelitis

\section{John D. Rodgers ${ }^{1 *}$, John J. McCullagh ${ }^{1}$, Perpetua T. McNamee ${ }^{2}$, Joan A. Smyth} and Hywel J. Ball ${ }^{3}$.

\section{Abstract}

This study aimed to develop an enzyme linked immunosorbant assay to detect antibody associated with Staphylococcus aureus that is produced during the chicken immune response to this organism. The protein nuclease was tested for suitability as an antigen to detect antibody in sera from broiler chickens that had been exposed to aerosolised $S$. aureus on day 1 post hatch during experiments to reproduce bacterial chondronecrosis and osteomyelitis. An ELISA was developed to measure the levels of nuclease antibody in 509 chicken sera from various experiments which also enabled the examination of the influence of factors such as the $S$. aureus infection status and co-infection with chicken anaemia virus (CAV) and infectious bursal disease virus (IBDV) on nuclease antibody levels. Positive levels of nuclease antibody were detected in $71 \%$ of serum samples from chickens inoculated with $S$. aureus, CAV and IBDV whilst positive levels were detected in $35 \%$ of chickens inoculated with $S$. aureus only. The influence of CAV and IBDV on the number of chickens with positive levels was most prominent in chickens aged up to 42 days. The study showed that nuclease specific antibodies form part of the humoral immune response in broiler chickens that have been exposed to $S$. aureus. Co-infection with CAV and IBDV appeared to promote development of antibody in birds younger than 42 days, however the presence of antibody did not necessarily prevent systemic infection. 


\section{Introduction}

Staphylococcus aureus can cause several disease conditions in poultry including septicaemia and skeletal infections in broiler chickens (Jordan, 1996). In a survey of Northern Ireland broiler chickens, the predominant cause of lameness was identified as bacterial chondronecrosis and osteomyelitis (BCO) of the femur and tibiotarsus that was associated with S. aureus (McNamee et al., 1998). However S. aureus has often been recovered from poultry regardless of their health status (Devriese et al., 1975; Thompson et al., 1980) suggesting that factors additional to the presence of the bacterium in a flock are important for the initiation of disease.

In a model of $S$. aureus induced BCO in broiler chickens developed by McNamee et al. (1999), an increase in BCO incidence was observed in broilers that were also exposed to chicken anaemia virus and infectious bursal disease virus. Because these viral agents have immunosuppressive qualities (Qureshi et al., 1998; Adair, 2000), the function of the avian immune system was likely to be a key factor in the initiation of this S. aureus associated disease. Whilst the innate immune response is believed to play a crucial role in preventing $S$. aureus infections in poultry (Zhu \& Hester, 2000), the importance of the adaptive immune response has not been as widely investigated. A number of recent studies have examined cell-mediated responses following exposure to $S$. aureus but studies detailing the humoral response are rare (Zhu \& Hester, 2000).

Williams-Smith (1954) reported a humoral response after subcutaneously inoculating chickens with a live broth culture of $S$. aureus. However no studies have been published that describe the humoral response in chickens exposed to $S$. aureus by a natural route. In studies aimed at detecting $S$. aureus antibody in other host species, 
ELISA methods have used many different antigens and no single antigen has been shown to be clearly indicative of infection (Scott-Adams et al., 1988; Ryding et al., 2002). An extra-cellular protein, nuclease, secreted by $S$. aureus was identified by Scott-Adams et al. (1988) as an immunodominant protein associated with bovine mastitis. Proteins with nuclease activity are secreted by $S$. aureus, S. hyicus and certain other staphylococci (Kloos \& Bannermann, 1999), and may constitute suitable ELISA antigens to detect specific immune responses in poultry to these organisms.

In this study, a commercially purified preparation of the $S$. aureus protein nuclease was tested for suitability as an antigen to detect antibody associated with $S$. aureus in sera from chickens that had been exposed to aerosolised S. aureus during experiments concerning the model for BCO in broiler chickens (McNamee et al., 1999). The influence of the age of the bird, $S$. aureus infection status and the CAV and IBDV infection status on the levels of $S$. aureus antibody present was also determined.

\section{Materials and Methods}

S. aureus and virus strains. A $S$. aureus strain recovered from a naturally occurring case of BCO, designated Isolate 24 was used (McNamee et al., 1999). Pulsed field gel electrophoresis has characterised this strain as the predominant type recovered from broilers with clinical disease in Northern Ireland (McCullagh et al., 1998). The CAV and IBDV strains used were CUX1 and G9 respectively (McNamee et al., 1999). 
Sera. All sera tested were collected from broiler chickens that were examined and bled at necropsy during the development of the model for BCO (McNamee et al., 1999) and subsequent experiments (Table 1). The broilers (Ross, Midlothian, UK) were hatched and reared in negative pressure isolators from day one until necropsy. They were observed twice daily for lameness and any lame birds were removed immediately and bled at necropsy. In general, two to five non-lame birds were removed from each group and bled during necropsy at 20 days post exposure to $S$. aureus and then every five days thereafter until the end of the experiment, to avoid overcrowding in the isolators. All work was undertaken in accordance with the United Kingdom Animals (Scientific Procedures) Act 1986 under the auspices of the Veterinary Sciences Division Ethics Review Committee.

All of the chickens inoculated with $S$. aureus were exposed to live broth culture of the bacteria by aerosol from a trigger sprayer at one-day-old (day one of the experiment). All of the chickens that were inoculated with either CAV alone, IBDV alone or both viruses were inoculated on day 21 of the experiment. Inoculation for CAV was by intramuscular injection and inoculation for IBDV was by eye drop.

Three hundred and thirty of the 417 chickens that donated sera and were inoculated with S. aureus alone or S. aureus and CAV and / or IBDV, were examined by culture for the presence of $S$. aureus. At post mortem examination, samples of the proximal end of femur and tibiotarsus from each leg and liver were cultured individually for S. aureus as described before (McNamee et al., 1999). Chickens that were identified as having S. aureus present in either liver or leg bone samples were classed as positive by bacteriology. 
ELISA methods. All reagents were used at $100 \mu$ l per microtitre well, except the final sulphuric acid stage to stop the enzyme reaction, which was used at $50 \mu \mathrm{l}$ per well. The optimum dilution of each reagent was determined by titration. The ELISA used phosphate buffered saline (PBS) (0.1 M, pH 7.2) to prepare wash fluid (PBS $+0.05 \%$ Tween-80) and reagent/sample dilution buffer PTN (PBS with an additional $2.85 \% \mathrm{NaCl}$ and $0.04 \%$ Tween-80).

The antigen used for the ELISA was purified micrococcal nuclease (SigmaAldrich, Poole, UK) isolated from S. aureus strain Foggi. The nuclease was stored in aliquots at $-20^{\circ} \mathrm{C}$ at a concentration of $8.4 \mathrm{mg} / \mathrm{ml}$ of distilled water.

Each chicken serum ELISA test, included three controls; an antigen coated well + conjugate-only control, an uncoated well with chicken serum + conjugate-only control, and an uncoated well with conjugate-only control. Duplicate wells were used for both the chicken serum ELISA tests and for the uncoated well with chicken serum + conjugate-only controls.

Nuclease diluted 1:800 in coating buffer (0.05 M carbonate buffer, $\mathrm{pH} 9.5)$ was used to coat wells overnight at $4{ }^{\circ} \mathrm{C}$. The wells were emptied and $3 \%$ bovine serum albumin (BSA) in coating buffer was added to each well for $1 \mathrm{~h}$ at $37^{\circ} \mathrm{C}$. Following washing with five changes of wash fluid, the chicken serum diluted 1:1000 in PTN was added for $1 \mathrm{~h}$ at $37^{\circ} \mathrm{C}$. The wells were washed and the peroxidase-conjugated rabbit anti-chicken IgY (Jackson Immunoresearch Laboratories Inc, Pennsylvania, USA) diluted 1:8000 in PTN was added for $1 \mathrm{~h}$ at $37^{\circ} \mathrm{C}$. After a final wash, the tetramethylbenzidine substrate (E solution, Chemicon, California, USA) was added to each well and held at 37 
${ }^{\circ} \mathrm{C}$. After $10 \mathrm{~min}$ the reaction was stopped with $2.5 \mathrm{M}$ sulphuric acid and the absorbance read at $450 \eta \mathrm{m}$ using an Original Multiskan RC ELISA plate reader (Thermolabsystems, Finland).Each microtitre plate included a positive control chicken serum (high nuclease antibody level) and a negative control chicken serum (low nuclease antibody level) that had been selected from stored samples during development of the ELISA. Non-specific antibody binding in the chicken serum + conjugate-only control was highly variable between sera, therefore the test result for each serum was calculated as the average chicken serum value minus the average chicken serum + conjugate-only control value. The relative antibody level (RAL) for each serum was then calculated by the following equation.

\section{(Chicken serum result - Negative control chicken serum result)}

Relative antibody level =

(Positive control serum chicken result - Negative control chicken serum result)

The positive / negative cut-off point for the ELISA was calculated as the average RAL for the 56 sera from control birds aged between 15 and 49 days that had not been inoculated with $S$. aureus, plus four times the standard deviation. The 56 sera from control birds produced a mean RAL of -0.0012 with a standard deviation of 0.0113 . Therefore sera with a RAL of 0.044 or higher were classed as positive in the ELISA.

\section{Results}

Nuclease ELISA survey results for day old chickens. The ELISA detected positive 
levels of nuclease antibody in 13 of 36 (36 \%) day-old chicks. The average RAL for dayold chicks was 0.07 and the average positive RAL for the day old chicks was 0.2.

\section{Nuclease ELISA survey results for birds inoculated with $S$. aureus alone or with}

viruses. The ELISA detected positive levels of nuclease antibody in $64 \%$ of the 417 sera samples taken from chickens that were inoculated with either S. aureus alone or with CAV and / or IBDV. The RALs were highest in the older chickens of all the groups tested (Figures 1, 2, 3, 4). A summary of results obtained for sera samples taken from chicken inoculated with $S$. aureus alone or S. aureus and CAV and / or IBDV is shown in Table 2. The overall percentage of positive results in sera from chickens inoculated with S. aureus alone was $35 \%$ and the average positive RAL was 0.49 . The percentage of positive results from chickens inoculated with $S$. aureus and CAV plus IBDV was $71 \%$ and the average positive RAL was 0.47 . In chickens aged up to 42 days, positive reactors were detected in $8 \%$ of birds exposed to $S$. aureus alone and in $68 \%$ of those exposed to S. aureus, CAV plus IBDV.. In chickens aged above 42 days, positive reactors were detected in $83 \%$ of birds exposed to $S$. aureus alone and in $74 \%$ of those exposed to $S$. aureus, CAV plus IBDV. In chickens from the $S$. aureus plus CAV group, positive reactions were detected in $85 \%$ of birds with an average positive RAL of 0.42 . Positive reactions were detected in $66 \%$ of chickens from the $S$. aureus plus IBDV group with an average positive RAL of 0.46 .

Of the 330 chickens that were examined by culture for $S$. aureus infection, the ELISA detected positive levels of nuclease antibody in 116 of $171(68 \%)$ and 110 of 159 $(69 \%)$ of sera from chickens that were culture-positive and culture-negative respectively 
(Figure 5). The average positive test RAL was 0.47 for both sera taken from culturepositive chickens and that from culture-negative chickens. Within each of the experimental sub groups, similar numbers of chickens with positive levels of nuclease were detected in the both culture-positive and culture-negative chickens (Table 3).

\section{Discussion}

The main finding of this study is that nuclease specific antibodies form part of the humoral immune response in broiler chickens that have been exposed to aerosolised $S$. aureus in a model of BCO. Furthermore, these nuclease specific antibodies appeared to develop earlier in birds that were co-infected with CAV and IBDV.

The initial findings of this study showed raised nuclease RAL values in some dayold control chickens, whilst the RAL values for 56 control chickens aged 15 days and older all had very low RAL values. This suggests transfer of maternal antibody from parents that fades from circulation by two weeks. Similar findings have been observed for maternal transfer of antibody specific for Salmonella spp. and Camplyobacter spp. in chicks (Hassan \& Curtis, 1996; Sahin et al., 2001). Consequently the positive/negative cut-off point in this study was calculated from RAL levels in control chickens aged 15 days or older to avoid the influence of maternal antibodies.

When results from the chicks younger than 15 days were excluded, the detection of RAL positive birds increased with time and may be related to the period required to generate an immune response following bacterial challenge and interaction with the immune system. Other studies that have examined chickens infected with bacterial 
pathogens have reported time periods of 1-3 weeks after infection before specific antibody was detected in serum (Lee et al., 1983; Chart et al., 1992).

The skin and feathers of birds that are exposed to $S$. aureus spray as described in this paper, have been swabbed for culture and have demonstrated S. aureus colonisation (unpublished data), however the degree of colonisation will be dependant on the other competitive bacterial flora present. In our study, not all birds exposed to $S$. aureus in a group became nuclease antibody-positive at the same time and some birds did not become positive at all. This would suggest that any interaction between the adaptive immune system and the bacterium might not occur on day 1 in all chickens sprayed with S. aureus. This may be a result of the infection method, as the intensity, route and timing of bacterial interactions with the adaptive immune system of each chick were not defined. After spraying, the bacterium has the potential to interact with the adaptive immune system via injury to the skin following colonisation of the skin and feathers (Zhu \& Hester, 2000). Interactions following spraying may also occur via direct deposition of aerosolised bacterium within the respiratory tract immediately after spraying and in the longer term the respiratory tract may be exposed to $S$. aureus present on dust generated from colonised skin and feathers (McNamee et al., 1999).

Therefore regardless of the route of challenge, an interaction is likely to increase with time as $S$. aureus probably colonises the skin and feathers of the chickens for the duration of the experiment. However, early interactions with the chicken immune system may not result in an immediate detectable response as the immune system of newly hatched chicks may be functionally immature in the first week of life (Holt et al., 1999). Therefore the significant host/bacteria interactions resulting in a detectable humoral 
immune response are most likely to occur once the immune system has become functionally mature. Another variable that will influence the immune response following aerosol exposure is the degree of bacterial exposure to the immune system, as humoral responses in chicken to many antigens have been shown to be dose dependant (Gross, 1985). The birds that had negative RALs may have initiated a low level interaction, no interaction or an interaction before the immune system matured.

Thus the aerosol spray inoculation method had potential for variation in the route, timing and intensity of any interaction between the challenging S. aureus and the host. This, coupled with variations of host immune status, are likely to be key factors behind the staggered increase in the nuclease RALs over time for birds exposed to S. aureus by spray at day one.

The percentage of positive nuclease RALs in birds aged under 42 days that had been inoculated with $S$. aureus plus the viruses was much greater than the percentage in similar birds inoculated with $S$. aureus alone (Table 2). The viral pathogens used in the model can cause periods of immunosuppression in the infected birds. CAV can deplete circulating lymphocytes and heterophils and depress cell-mediated immune responses (Adair, 2000). IBDV can reduce antibody levels in chicks (Qureshi et al., 1998) and suppress the function of heterophils and macrophages (Lam, 1998). Therefore the higher RAL values in birds from groups inoculated with viruses may be due to immunosuppression of the chicken, allowing $S$. aureus to invade and infect more readily, presumably stimulating the host immune system and allowing the development of detectable response during recovery from the immunosuppressive period. The influence of viral challenge appears less significant after 42 days since similar percentages of 
positive birds and similar average RAL values were observed in either virus-exposed groups or non-exposed groups (Table 2). However, this period is well after the transient stage of immunosuppression associated with the viral infections (Adair, 2000; Sharma et $a l ., 2000)$, and is an indication of the invasive capacity of the $S$. aureus strain used; i.e. it was capable of initiating an immune response in birds that were not virus infected that is similar to virus infected birds, but over a longer time span. After 42 days, birds that were not exposed to viruses had had an increased time for an $S$. aureus-host interaction and the subsequent immune response to develop. The main influence of the viruses on nuclease RAL may be just to accelerate the antibody development in this model rather than actually promote higher levels in viral exposed birds.

In groups inoculated with a single virus, the percentage of birds aged up to 42 days with positive nuclease RALs was much higher in the CAV group (91\%) compared to the IBDV group (45\%), although the numbers in these groups were small. The differences observed between the single virus-exposed groups may suggest that immunosuppressive qualities of CAV were predominantly responsible for the raised percentage of positive birds observed from groups infected with both viruses. Alternatively, the lower level of positive birds in IBDV infected groups may have been the result of the virus lowering antibody levels to non-detectable levels at the immunosuppressive stage, as has been found in previous studies (Qureshi et al., 1998).

No relationship was observed between nuclease RAL in an individual bird and the corresponding bacteriology culture result for S. aureus in the liver and the leg bones. As discussed above the nature of bacterial challenge to individual birds may be variable, making assumptions on infection status based on the nuclease RAL impossible, as several 
different scenarios may have existed. A positive RAL result for a bird may indicate that its adaptive immune system has encountered $S$. aureus. However based on the findings from this study a positive RAL value cannot differentiate between an infected bird and a bird that has resisted a $S$. aureus challenge. Additionally, negative RAL results may be obtained for birds that have been challenged or infected if the serum samples are taken during the acute phase of an immune response. A similar scenario was observed by Berchieri et al., (1998) when looking for Salmonella specific antibody in sera from Salmonella infected poultry flocks, where the organism was isolated from birds before detectable levels of antibody appeared in circulation at two weeks post infection. Alternatively a negative nuclease RAL may result from an insufficient interaction between $S$. aureus and the adaptive immune system or the influence of IBDV on antibody level as discussed earlier.

In summary, this report describes an ELISA that is capable of detecting the presence of nuclease antibodies associated with $S$. aureus, and provides some information on the humoral response on the BCO model. The ELISA has shown the influence of CAV and IBDV, which appear to raise the percentage of chickens, aged up to 42 days, that demonstrate a positive nuclease RAL. The ELISA results suggest that maternal nuclease antibody is transferred to newborn chicks but that the maternal antibody does not remain past two weeks. No obvious relationship was observed between the RAL values obtained in sera from BCO model experiments and bacteriological culture test results for the presence of $S$. aureus in the leg bones and liver. 


\section{Acknowledgements}

The authors are grateful to Cobb Breeding Company UK Ltd., Moy Park Ltd., Nutec Ltd., Elanco Animal Health Ltd., O’Kane Poultry Ltd. and Ross Breeders UK Ltd. for financial support and to the bacteriology staff of the Veterinary Sciences Division, Belfast for technical assistance.

\section{References}

Adair, B.M. (2000). Immunopathogenesis of chicken anaemia virus infection. Developmental and Comparative Immunology, 24, 247-255.

Berchieri Jr, A., IBA, A-M. \& Barrow, P.A. (1996). Examination by ELISA of sera obtained from chicken breeder and layer flocks showing evidence of fowl typhoid or pullorum disease. Avian Pathology, 24, 411-420.

Chart, H., Baskerville, A., Humphreys, T.J. \& Rowe, B. (1992). Serological responses of chickens experimentally infected with Salmonella enteritidis PT4 by different routes. Epidemiology and Infection, 109, 297-302.

Devriese, L.A., Devos, A.H. \& Van Damme, L.R. (1975). Quantitative aspects of the Staphylococcus aureus flora of poultry. Avian Diseases, 54, 95-101.

Gross, W.B. (1986). Effects of dose of antigen and social environment on antibody response of high and low antibody response chickens. Poultry Science, 65, 687-692.

Hassan, J.O. \& Curtiss III, R. (1996). Effect of vaccination of hens with an avirulent strain of Salmonella typhimurium on immunity of progeny challenged with wild-type Salmonella strains. Infection and Immunity, 64, 938-944.

Holt, P.S., Gast, R.K., Porter, R.E. \& Stone, H.D. (1999). Hyporesponsiveness of 
systemic and mucosal humoral immune response systems in chickens infected with Salmonella enterica serovar enteritidis at one day of age. Poultry Science, 78, 15101517.

Jordan, F.T.W. (1996). Staphylococci. In F.T.W. Jordan and M. Pattison (Eds). Poultry Diseases, 4th edn (pp 66-70). London, UK: W. B. Saunders Company Ltd..

Kloos, W.E. \& Bannermann, T.L. (1999). Staphylococcus and Micrococcus. In P.R. Murray, E. Baron, M.A. Pfaller, F.C. Tenover \& R.H. Yolken (Eds.). Manual of Clinical Microbiology, 7th edn (pp.264-282). Washington DC, USA: American Society of Microbiologists.

Lam, K.M. (1998). Alteration of chicken heterophil and macrophage functions by the infectious bursal disease virus. Microbial Pathogenesis, 25, 147-155.

Lee, G.M., Jackson, G.D.F \& Cooper, G.N. (1983). Infection and immune responses in chickens exposed to Salmonella typhimurium. Avian Diseases, 27, 577-583.

McCullagh, J.J., McNamee, P.T., Ball, H.J. \& Smyth, J.A. (1998). The use of pulsedfield gel electrophoresis to investigate the epidemiology of Staphylococcus aureus infection in commercial broiler flocks. Veterinary Microbiology, 63, 275-281.

McNamee, P.T., McCullagh, J.J., Thorp, B.H., Ball, H.J., Graham, D., McCullough, S.J., McConaghy, D. \& Smyth, J.A. (1998). Study of leg weakness in two commercial broiler flocks. Veterinary Record, 143, 131-135.

McNamee, P.T., McCullagh, J.J., Rodgers, J.D., Thorp, B.H., Ball, H.J., Connor, T.D., McConaghy, D. \& Smyth, J.A. (1999). Development of an experimental model of bacterial chondronecrosis with osteomyelitis in broilers following exposure to Staphylococcus aureus by aerosol, and inoculation with chicken anaemia and 
infectious bursal disease viruses. Avian. Pathology, 28, 26-35.

Qureshi, M.A, Hussain, I. \& Heggen, C.L. (1998). Understanding immunology in disease development and control. Poultry Science, 77, 1126-1129.

Ryding, U., Espersen, F., Soderquist, B \& Christensson, B. (2002). Evaluation of seven different enzyme-linked immunosorbant assays for serodiagnosis of Staphylococcus aureus bacteremia. Diagnostic Microbiology and Infectious Disease, 42, 9-15.

Sahin, O., Zhang, Q., Meitzler, J.C., Harr, B.S., Morshita, T.Y. \& Mohan, R. (2001). Prevalence, antigenic specificity, and bacterial activity of poultry anti-Camplyobacter maternal antibodies. Applied and Environmental Microbiology, 67, 3951-3957.

Scott-Adams, D., McDonald, J.S., Hancock, D. \& McGuire, T.C. (1988).

Staphylococcus aureus antigens reactive with milk immunoglobulin G of naturally infected dairy cows. Journal of Clinical Microbiology, 26, 1175-1180.

Sharma, J.M., Kim, I-J., Rautenschlein, S., \& Yeh, H-Y. (2000). Infectious bursal disease of chickens: pathogenesis and immunosuppression. Developmental and Comparative Immunology, 24, 223-235.

Thompson, J.K., Gibbs, P.A. \& Patterson, J.T. (1980). Staphylococcus aureus in commercial laying flocks: Incidence and characteristics of strains isolated from chicks, pullets and hens in an integrated commercial enterprise. British Poultry Science, 21, 315-330.

Williams-Smith, H., (1954). Experimental staphylococcal infection in chickens. Journal of Pathological Bacteriology, 67, 81-87.

Zhu, X.Y. \& Hester, P.Y. (2000). The etiology of staphylococcosis. Avian and Poultry Biology Reviews, 11, 97-112. 
Table 1. Details of the sera tested by the ELISA for nuclease antibody

\begin{tabular}{llll}
\hline Sera group & Number of sera & Age of donor birds & Inoculation details \\
\hline Control & 56 & $15-49$ days & No inoculation \\
Day old & 36 & 1 day & No inoculation \\
A & 96 & $13-50$ days & S. aureus \\
B & 221 & $23-50$ days & S. aureus + CAV +IBDV \\
C & 41 & $22-46$ days & S. aureus + CAV \\
D & 59 & $27-36$ days & S. aureus + IBDV \\
\hline
\end{tabular}

Table 2. Number of chickens from the complete survey with a positive nuclease relative antibody level (RAL) and the average positive $R A L$ in groups of chickens after inoculation with $\mathrm{S}$. aureus alone or $\mathrm{S}$. aureus with $C A V$ and/or IBDV ${ }^{a}$

\begin{tabular}{lllllllll}
\hline $\begin{array}{l}\text { Sera } \\
\text { group }\end{array}$ & $\begin{array}{l}\text { Number } \\
\text { Tested }\end{array}$ & $\begin{array}{l}\text { Number } \\
\text { Positive }\end{array}$ & $\begin{array}{l}\% \\
\text { positive }\end{array}$ & $\begin{array}{l}\text { Average positive } \\
\text { RAL }\end{array}$ & $\begin{array}{l}\text { Number tested } \\
\text { up to 42 day old }\end{array}$ & $\begin{array}{l}\% \\
\text { positive }\end{array}$ & $\begin{array}{l}\text { Number tested } \\
\text { above 42 day old }\end{array}$ & $\begin{array}{l}\% \\
\text { positive }\end{array}$ \\
\hline A & 96 & 34 & 35 & 0.49 & 61 & 8 & 35 & 83 \\
B & 221 & 159 & 71 & 0.47 & 112 & 68 & 109 & 74 \\
C & 41 & 35 & 85 & 0.42 & 11 & 91 & 30 & 83 \\
D & 59 & 39 & 66 & 0.46 & 29 & 45 & 30 & 87 \\
\hline
\end{tabular}

\footnotetext{
${ }^{\mathrm{a}}$ All test results based on average values obtained from duplicate test wells.

$\mathrm{A}=$ Sera from birds after inoculation with $S$. aureus on day one.

B = Sera from birds after inoculation with S. aureus on day one plus CAV + IBDV on day 21 .

$\mathrm{C}=$ Sera from birds after inoculation with $S$. aureus on day one plus CAV on day 21.

$\mathrm{D}=$ Sera from birds after inoculation with S. aureus on day one plus IBDV on day 21.
} 
Table 3. The percentage of positive nuclease relative antibody level (RAL) results in chickens that were tested for $\mathrm{S}$. aureus infection by culture

\begin{tabular}{llll}
\hline $\begin{array}{l}\text { Experimental } \\
\text { Group }\end{array}$ & $\begin{array}{l}\text { S. aureus bacteriology } \\
\text { result }\end{array}$ & Number tested & $\begin{array}{l}\text { Percentage tested with positive RAL for } \\
\text { nuclease }\end{array}$ \\
\hline A & Positive & 34 & 56 \\
& Negative & 26 & 54 \\
B & Positive & 96 & 67 \\
& Negative & 90 & 71 \\
C & Positive & 25 & 84 \\
& Negative & 10 & 80 \\
D & Positive & 16 & 75 \\
& Negative & 33 & 73 \\
TOTAL & Positive & 171 & 68 \\
& Negative & 159 & 69 \\
\hline
\end{tabular}

$\mathrm{A}=$ Sera from birds after inoculation with S. aureus on day one.

$\mathrm{B}=$ Sera from birds after inoculation with S. aureus on day one plus CAV + IBDV on day 21 .

$\mathrm{C}=$ Sera from birds after inoculation with $S$. aureus on day one plus CAV on day 21.

$\mathrm{D}=$ Sera from birds after inoculation with S. aureus on day one plus IBDV on day 21. 


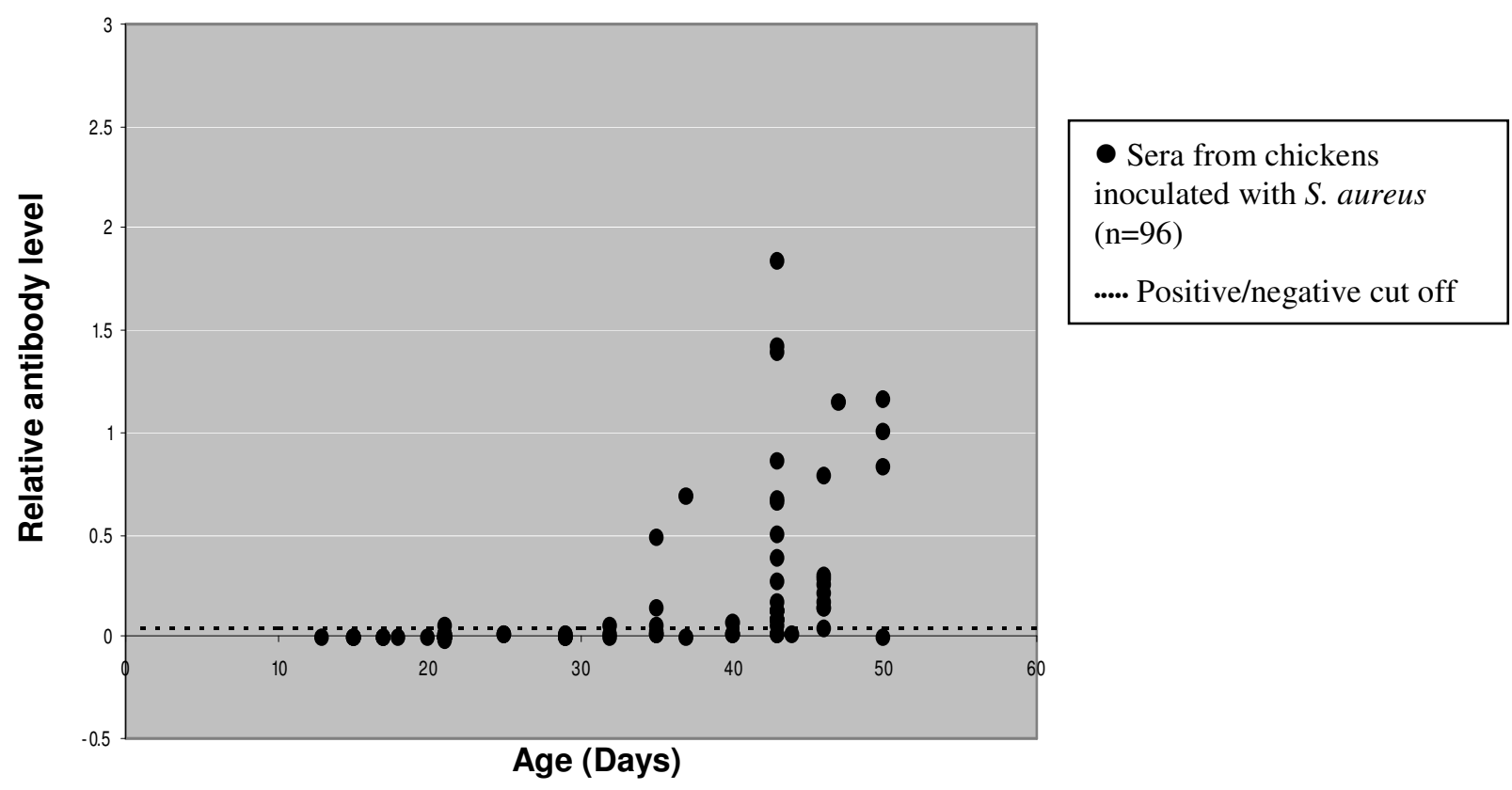

Figure 1. Nuclease antibody in sera from chickens of various ages after inoculation with $\mathrm{S}$. aureus on day 1.

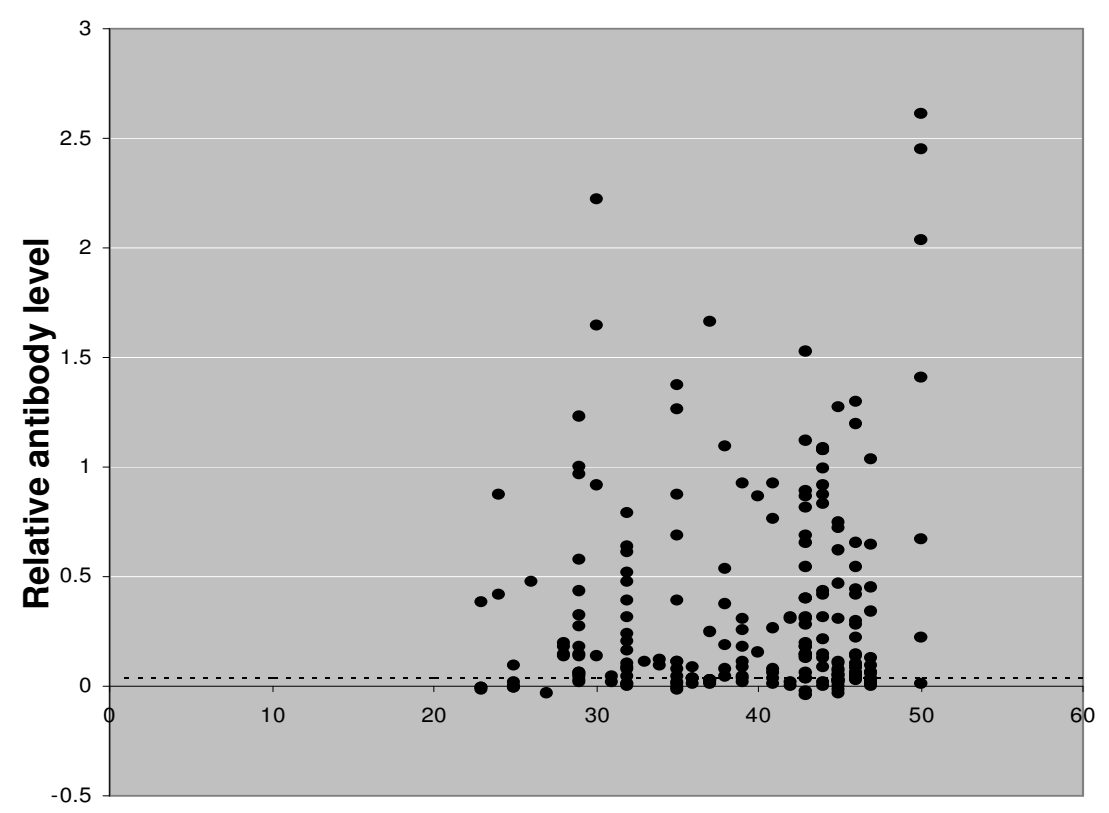

- Sera from chickens inoculated with $S$. aureus and CAV + IBDV $(n=221)$

..... Positive/negative cut off

\section{Age (Days)}

Figure 2. Nuclease antibody in sera from chickens of various ages after inoculation with $\mathrm{S}$. aureus on day 1 and chicken anaemia virus (CAV) and infectious bursal

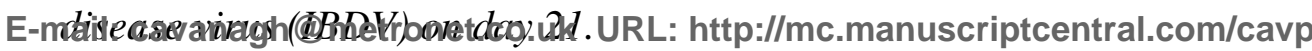




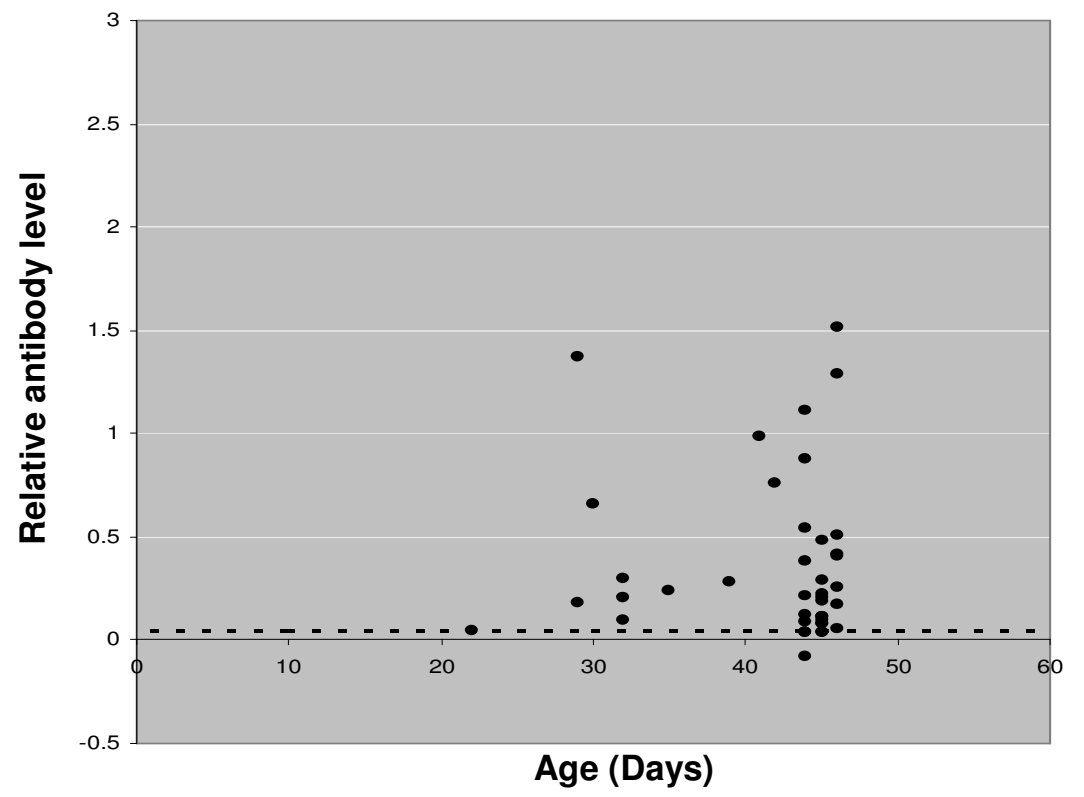

- Sera from chickens inoculated with $S$. aureus and $\operatorname{CAV}(\mathrm{n}=41)$

..... Positive/negative cut off

Figure 3. Nuclease antibody in sera from chickens of various ages after inoculation with $\mathrm{S}$. aureus on day 1 and chicken anaemia virus (CAV) on day 21.

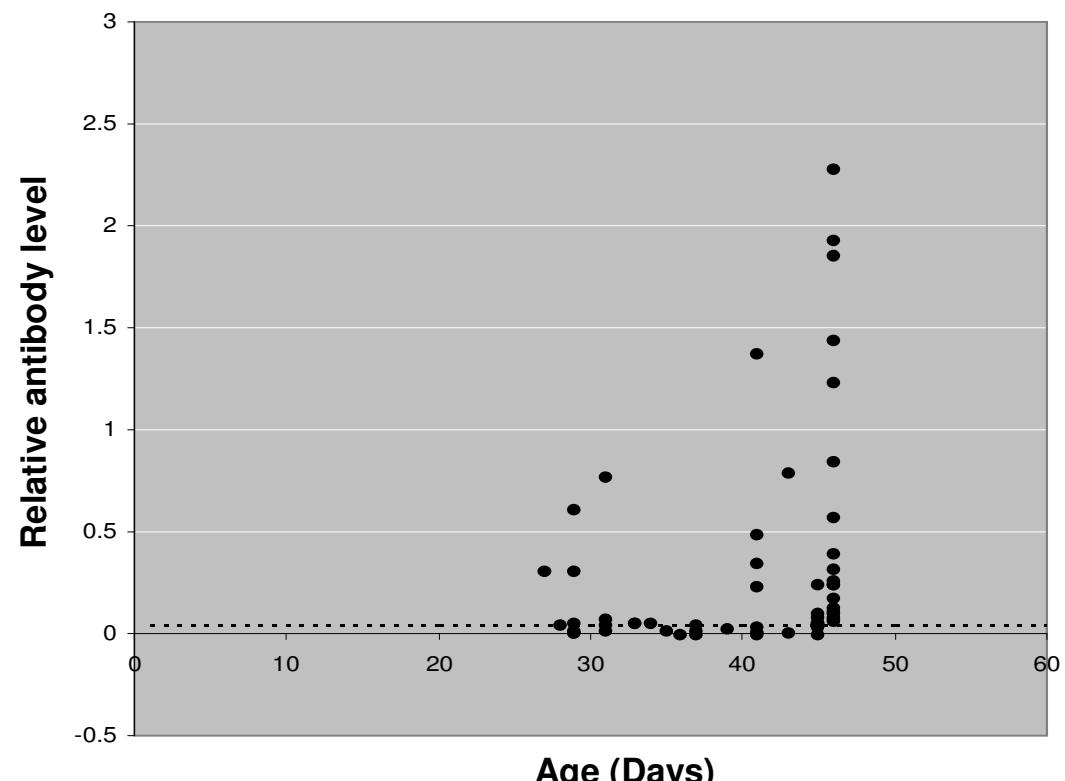

- Sera from chickens inoculated with $S$. aureus and IBDV $(\mathrm{n}=59)$

..... Positive/negative cut off

Figure 4. Nuclease antibody in sera from chicken of various ages after inoculation with $\mathrm{S}$. aureus on day 1 and infectious bursal disease virus (IBDV) on day 21. 


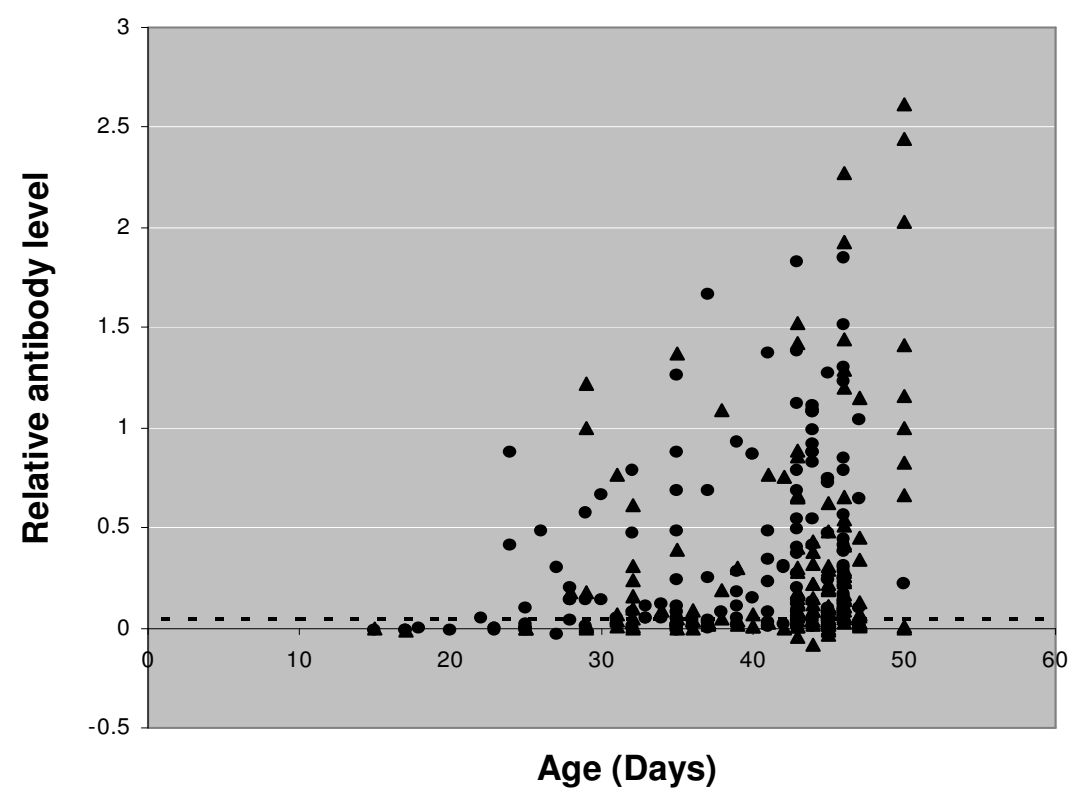

Positive culture $(n=171)$

$\Delta$ Negative culture $(n=159)$

.... Positive/negative cut off

Figure 5. Nuclease antibody in sera of chickens that tested either negative or positive by culture for $\mathrm{S}$. aureus following inoculation with $\mathrm{S}$. aureus alone or S. aureus and chicken anaemia virus and / or infectious bursal disease virus. 